\title{
Syntactic Projectability and Co-Participant Completion in Japanese Conversation
}

\author{
POLLY SZATROWSKI \\ University of Minnesota
}

\section{Introduction}

In this paper, I investigate the role of syntax in projecting possible ends of utterances. Research on turn-taking and co-participant completion has concluded that co-participants use many concomitant features of talk-in-interaction in addition to grammatical structure to project the ends of utterances. My purpose is not to refute the contribution of these concomitant features, but rather to refine further the role of grammatical structure in syntactic projectability.

The notion of projectability has been a key concept for determining the place where turn transition is relevant in conversation analytic research. According to Sacks, Schegloff, \& Jefferson (1974:702), speakers construct turns using sentences, clauses, phrases, and lexical constructions which "allow a projection of the unit-type under way, and what, roughly, it will take for an instance of that unit-type to be completed." I will use the term syntactic projectability to refer to the ability to project a syntactic category that may come later in an utterance. I define co-construction as the creation of a relative clause, clause, simple or complex sentence by 2 or more participants. I will mark co-participant completions, that is, the completion of one speaker's utterance by another participant, with an arrow in the examples in this paper.

Research by Fox et al. (1996) and Hayashi (1999) contrast the tightly knit clause structure in English to loosely connected elements in Japanese, and use this as a basis for claiming that Japanese lacks "early projection" strategies. I hypothesize that co-construction will be more likely when there is higher syntactic projectability and restriction on what comes later in a sentence, and will demonstrate that there are syntactic practices in Japanese which allow for early projection.

\section{Previous research on co-construction}

In this section, I will review research related to co-construction by Lemer (1991), Mizutani (1993), Fox et al. (1996), and Hayashi (1997). Then I will introduce Minami's model for Japanese syntax which I will use in Section 3 to analyze 
syntactic projectability in Japanese.

Lerner (1991:444) defines a "compound turn constructional unit (TCU)" as "[a]ny turn unit which in the course of its construction projects a [preliminary component + final component] format" as in (1). K projects what comes next from D's 'if' clause, and completes the compound TCU.

(1) 1D: so if one person said he couldn't invest

$\rightarrow 2 \mathrm{~K}$ : then I'd have to wait (Lerner 1991:445)
Preliminary Component

Final Component

Mizutani (1993:7) suggests that co-construction is possible in Japanese because one can project the end of an utterance from modal adverbs and conjunctions. Modal adverbs such as doo mo 'somehow', doo yara 'somehow', tyotto 'a bit', nan to naku 'somehow' link with sentence endings, and clauses which follow conjunctive expressions such as no de 'because', kara 'because', mono desu kara 'because' vary depending on the conjunctive expression.

In a study of repair and projectability in Japanese and English, Fox et al. (1996:208-214) found that the elements in Japanese do not always form a coherent syntactic structure because $\mathrm{S}, \mathrm{O}$, and $\mathrm{V}$ are not always expressed, and the elements expressed "seem to be more independent from one another" than in English. English requires an overt subject as the "beginning" of its "tightly knit clause structure," and syntactic projection starts earlier in an utterance in English because the beginnings of TCUs project possible organizations for what is to follow. They conclude that Japanese participants are end-oriented, and "engage in syntactic practices which do not make easy 'early projection' strategies." Rather they use "wait and see" strategies, and projection is done bit-by-bit. "[T]he beginnings of TCUs in Japanese do not tend to have elements that syntactically project the possible organization of what is to follow."

Hayashi (1999) claimed that co-participant completion of Lerner's two-part compound TCU format is rare in Japanese. For example, after a-tara 'if' clause the co-participant rarely produces the equivalent of the 'then' clause in Japanese, rather the co-participant adds the final 1 or 2 words of the 'then' clause. In (2), the first speaker $\mathrm{H}$ continues after the -tara 'if' clause with the final component of the compound TCU and the co-participant M completes the final component with the final verb!

\footnotetext{
I TRANSCRIPTION NOTATION:

$/ /$ the part of the utterance after the // is overlapped by the next utterance

(0.5) numbers inside () give the length of a pause in tenths of seconds

$:$ colon indicates that the previous syllable is lengthened. number of colons reflects the amount of lengthening

? rising intonation (not necessarily a question)

, short pause, or continuing intonation

$\rightarrow \quad$ co-participant completion

The Japanese romanization follows that of Jorden with Noda (1987). Romanization of cited examples has been adjusted to maintain consistency.
} 
(2) $1 \mathrm{H}$ Okurahoma tte:: eego de hatuon-s tara: Preliminary Component Oklahoma QT English in pronounce-COND Iff (you) pronounce Oklahoma in English, $2 \mathrm{H}$ zenzen nihongo no Okurahoma to //ti- Final Component totally Japanese of Oklahoma from diflit., totally totally from the Japanese Okurahoma, //(it)'s dif$\rightarrow 3 \mathrm{M}$

tyau nen na different FP FP

(it)'s different, isn't it.

(Hayashi 1999:480; boxes and annotation mine)

Hayashi concluded that English clauses have a "tightly-knit" structure, and a great deal of information is given about how to end a clause in the first part of the clause. In contrast, Japanese has a looser syntactic structure and "projection is done more bit-by-bit" than in English, and co-participants use "wait and see" strategies (Hayashi 1999:495).

It is interesting to note that the initial element of the final component (a simple sentence) in $4 \mathrm{H}$ in (2) is zenzen 'totally,' a modal adverb which strongly restricts the predicate. Zenzen 'totally' projects a negative predicate, in this case tigau 'it is different' at the end of the sentence. Previous research by Japanese grammarians can help explain this projectability.

Minami $(1964,1974,1993,1997)$ proposed a model for the syntactic structure of sentences in Japanese which is based on results from extensive analysis of the occurrence of non-predicate components and predicate elements in the internal structure of subordinate clauses (Table 1). This model unifies and confirms results of research by many Japanese grammarians from this unique perspective.

Minami's model is like an onion. When you cut through an onion, the outer layer of the onion and the next layer is not connected. However, if you cut through to the middle, you will reach a point where the layers will connect back up on the other side. Like an onion with 4 layers, a Japanese sentence begins with non-predicate components, which are ordered in layers D, C, B, A, and these layers are followed by the predicate elements ordered A, B, C, D, in the reverse order. (3) is a made-up sentence with components/elements in all 4 levels.

GLOSS ABBREVIATIONS: CAUS $=$ causative, COHORT $=$ cohortative, COND $=$ conditional, $\mathrm{COP}=$ copula, $\mathrm{DO}=$ direct object, $\mathrm{EVID}=$ evidential, $\mathrm{FP}=$ final particle, $\mathrm{GER}=$ gerund, $\mathrm{IO}=$ indirect object, $\mathrm{NEG}=$ negative, NOM=nominalizer, $\mathrm{PASS}=$ passive, $\mathrm{PF}=$ perfective, $\mathrm{POT}=$ potential, $\mathrm{PROG}=$ progressive, $\mathrm{QP}=$ question particle, $\mathrm{QT}=$ quotative, $\mathrm{SUB}=$ subject, $\mathrm{TENT}=$ tentative, TOP=topic, $\mathrm{V}=$ verb 
(3) Nee, doo yara kinoo kanozyo ga Kenni kaimono o sa-se -ta rasii ne. hey somehow yesterday she SUB Ken IO shopping DO do-CAUS-PF EVID FP

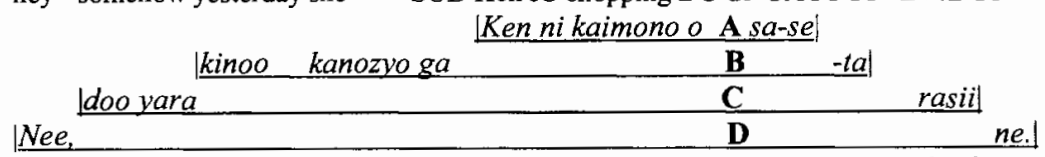

'Hey, somehow yesterday she made Ken do the shopping apparently, huh.'

The different levels are connected from the inside. The innermost level is the A level, the core semantic meaning of the sentence Ken ni kaimono o sa-se "make Ken do shopping'. The next level out is the B level, in which temporal adverbs such as kinoo 'yesterday' and the subject kanozyo 'she' connect with the perfective ending of the verb. Then, in the $\mathrm{C}$ level the modal adverb doo yara 'somehow' connects with the evidential rasii 'seems, evidently'. The outer D level is the most interpersonal, e.g., the attention request Nee 'Hey' connects with the final particle $n e$ 'huh'. In this paper, I will focus primarily on levels A, B, and C.

\section{Analysis}

In my analysis I will show how Minami's model can be used to analyze syntactic projectability in co-constructions of simple and complex sentences in Japanese. The data for this study consist of 35 examples of co-construction collected from natural conversations including everyday talk, company meetings, etc.

In the 20 examples of co-construction of simple sentences/clauses in my data, the co-participant used an $\mathrm{A}$ level component more often than a $\mathrm{B}$ or $\mathrm{C}$ level component to project the end of the speaker's utterance: $A(13)>B(4)>C(3)$.

Examples in which an A level component was used to project the completion included i) NP $o$ [direct object] $+\mathrm{V}$, ii) NP $n i$ [indirect object] $+\mathrm{V}$ as in (4), and iii) NP made 'until'/e 'to' + motion $\mathrm{V}$ as in (5).

(4) IR T-san wa nanka d(e)isizyon mitai no o itumo hito ni Mr. T TOP like decision like NOM DO always people IO

Mr. Tanaka like decision-like things always to people(the indirect object)

$\rightarrow 2 \mathrm{H}$ yudaneru entrust

(he) leaves it up to (them)

(Ono \& Yoshida 1996:118)

(5) $131 \mathrm{~K}$ zyaa, dokka sotti no oyazi no kaisva no hoo made, then somewhere there COP father of company of alternative up to Then somewhere, as far as my father's company there

$\rightarrow 132 \mathrm{~T}$ ittvaou.

(I) guess (I)'ll go. (Sakuma, Sugito, \& Hanzawa 1997: Data p.30)

There were 4 examples where the co-participant completed the speaker's 
utterance after a B level component; iv) NP ga [subject] + predicate as in (6) $)^{2}$ and v) B level modal adverb + predicate as in (2) and (7) (first $\rightarrow$ ).

(6) IY Nanka Papa no iikata_ga nee, somehow Papa of way of talking SUB you know Somehow Papa's [your] way of talking, you know

$\rightarrow 2 \mathrm{~A}$ moo iyami //da kara. really mean $\mathrm{COP}$ so is really mean so.

(Jones 1990:22-3)

Hata (1991) describes tinzyutu hukusi 'modal adverbs' as forms that "supplement and emphasize the modal meaning (negation, supposition, hypotheticality) of the predicate. Tinzyutu ... generally refers to the speaker's psychological state" (p.22; translation mine). Modal adverbs heighten projectability because they restrict the predicate. They have co-occurrence relations with negation (kessite ... nai[NEG] 'it never happens'), assertion/supposition (kitto ... daroo [TENT] 'for sure it must ...'), etc.

\section{(7) $33 \mathrm{~S}$ Tada tan $n i$ \\ Just simply}

$\rightarrow 34 \mathrm{~A}$ dokka no syatyoo-san to ka sa, tada aisatu ni kite sa, someplace of chief or FP just greeting for come-GER FP someplace's chief or you know, just comes for a greeting you know, and

$\rightarrow 35 \mathrm{~S}$ sositara, so, misete, then right show-GER

then, right, (we/you) show (it) and

(Kuwabara 1996:10)

Examples in which a $\mathrm{C}$ level component was used to project the completion included vi) NP $w a$ [topic] + predicate as in $(8)^{3}$, and vii) $\mathrm{C}$ level modal adverb (moshikasitara 'perhaps') + evidential (ka mo sirenai 'maybe') as in (9).

(8) 1H Soo yuu tyuuto hanpa na kanzi de that kind halfway COP feeling COP-GER With that kind of halfway feeling

$2 \mathrm{H}$ koo yattyatta tte iu no ga ga bokuwa this do completely-PF QT say NOM SUB I TOP (his) ending up doing (things) like this, $\underline{I}$, for one

$\rightarrow 3 \mathrm{~S}$ ikenai to omou go-POT-NEG QT think think it's wrong.

(Ono \& Yoshida 1996:125)

\footnotetext{
${ }^{2}$ The overall rarity of NP ga subjects in Japanese conversation suggests that subjects may not be the best thing on which to base a comparison of projection strategies.

${ }^{3}(8)$ is from a critical discussion about a married man who was flirting with a Japanese woman. The B level ga (SUB) component (dotted line) also projects the verb ikenai 'is wrong'.
} 
(9) 100H Soo suru to, kore, "siraseru" tte iu no mo, nanka, mosikasitara, then this inform QT say NOM also somehow perhaps then, this, "informing" too, somehow, perhaps $101 \mathrm{M}$ $N$. Uh huh.

$$
\begin{gathered}
102 \mathrm{H} \text { nanka, waketa hoo ga yokatta no. } \\
\text { somehow divide-PF alternative SUB good-PF FP } \\
\text { somehow, it's that it would have been better to divide } \\
\rightarrow 103 \mathrm{M} \text { ka mo sirenai } n \text { da kedo //ne: } \\
\text { maybe NOM COP but FP } \\
\text { it's that maybe (it is so) but, you know. }
\end{gathered}
$$
somehow divide-PF alternative SUB good-PF FP somehow, it's that it would have been better to divide (it)

When an outer level component is used to project the end of a simple sentence/clause, the first speaker may add more components/elements before the co-participant completion. That is, the first speaker may add inner level components before the final projected one is reached as in (2) and (9).

Although Hayashi (1996) claimed that co-construction of compound TCUs is rare in Japanese, I found 15 examples in my data. Following Minami (1964:85, 1997:31), I will treat A level -te gerund clauses as predicate rather than sentence modifiers, and divide B level clauses into 3 types, B3, B2 and B1 (Table 1). The distribution of co-constructions of complex sentences in my data was: $\mathrm{B} 3(0)<\mathrm{B} 2(2)<\mathrm{B} 1(5)<\mathrm{C}(8)$.

According to Minami (1964:83-86, 1997:29-32), some B level subordinate clauses restrict while others do not restrict the predicate. For example, imperative and desiderative verb forms cannot occur after a node 'because' clause (Nagano 1952), and the past -ta form cannot occur after - $b a$ 'if' or -tara 'if' clauses (simple condition). In contrast, sequential clauses ending in the -te (gerund) or verb stem do not restrict the predicate.

There were 7 examples of co-participant completion of a complex sentence beginning with a $\mathrm{B}$ level clause; 5 after a sequential -te2 (GER) clause as in (7) (second $\rightarrow$ ), and 2 after a -tara 'if, when' clause as in (10).

(10) $3 \mathrm{H}$ modotte_ kuru no $\mathrm{ka}$ to omotTARA return-GER come NOM QP QT think-COND when (I) thought (he) would come back

$\rightarrow 4 \mathrm{~T}$ netyatta mitai

end up falling asleep-PF seems

(it) seems that (he) ended up falling asleep.

(Ono \& Yoshida 1996:123)

There were 8 examples of co-construction in which the co-participant completed a complex sentence beginning with a $\mathrm{C}$ level clause; 6 after a kara 
'because' clause as in (11), and 2 after a kedo(mo) 'but' clause as in (12). Both (11) and (12) are from invitation conversations. The inviter completes a sentence beginning with the invitee's dispreferred response.

(11) 49R dakara, osamaru tokoro ni, hora, osame//rarenai KARA nee. so put away place in you know put away-POT-NEG so you know so, (I) can't put (things) away in the places they belong so, you know

$\rightarrow 50 \mathrm{~N}$ A:a. Zyaa, toobun wa isogasii wake da. oh then a while TOP busy case COP $\mathrm{O}: \mathrm{h}$. Then, (it)'s that (you) will be busy for a while, at least.

(Szatrowski 1993: Data p.18)

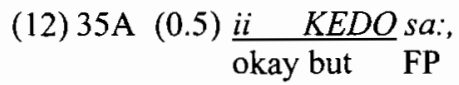
(it)'s okay but, you know,

$\rightarrow 36 \mathrm{~B} \frac{\text { Boroboro? }}{\text { (you)'re tired? }}$

(Szatrowski 1993: Data p.15)

\section{Conclusion}

I hypothesized that there would be more cases of co-construction when the first speaker used a component with higher syntactic projectability and more restriction on what would occur later in the utterance. However, my data suggested that the opposite was true. I summarize the results from my analysis of examples of co-construction of simple and complex sentences in my data using a continuum of semantic and syntactic projectability and restriction in coconstructions. The arrows indicate increasing frequency in my data.

In co-constructions of simple sentences, there were fewer examples with $C$, more with $\mathrm{B}$, and the most with $\mathrm{A}$ level components. In addition, most of the $\mathrm{B}$ and $A$ level components used for projection were core arguments with semantic connection with the verb, that is semantic projectability seemed stronger.

$$
\begin{aligned}
& \text { SIMPLE SENTENCE: A (13) } \leftarrow \text { B (4) } \leftarrow \quad \text { C (3) }
\end{aligned}
$$

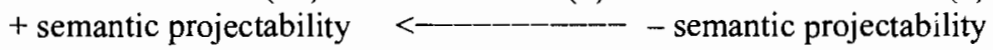

$$
\begin{aligned}
& \text { - syntactic projectability <-___-___- + syntactic projectability } \\
& \text { - restriction } \\
& + \text { restriction }
\end{aligned}
$$

In complex sentences, I found more examples with $\mathrm{C}$ than $\mathrm{B}$ level clauses. Again, co-participant completion seemed to be related more to semantic or pragmatic projectability. 
(14)

COMPLEX SENTENCE: $\quad \mathbf{B}_{3}(0) \quad \rightarrow \quad \mathbf{B}_{2}(2) \quad \rightarrow \quad \mathbf{B}_{1}(5) \quad \rightarrow \quad$ C (8)

- semantic projectability $\longrightarrow \longrightarrow-\longrightarrow+$ + semantic projectability

+ syntactic projectability $\longrightarrow-\longrightarrow-\longrightarrow-$ syntactic projectability

+ restriction

- restriction

In conclusion, in co-constructions of both simple sentences as well as complex sentences in Japanese, semantic/pragmatic projectability seemed to be a stronger factor than syntactic projectability. This supports Fox et al.'s (1996) claim that syntactic projection is not very strong in Japanese. However, contrary to Fox et al.'s claim that the beginnings of TCUs in Japanese do not tend to syntactically project the possible organization of what is to come, I found that there were initial components from which the co-participant could project later elements in the sentence. For example, outer $\mathrm{B}$ and $\mathrm{C}$ level components such as modal adverbs not only project the syntactic category of the element to follow, but also have strong co-occurrence restrictions on the actual lexical item that can fill that slot.

In head-initial languages like English, the negative head precedes the verb phrase, and because it is not dependent on the negative polarity item for licensing, it does not project the negative polarity item. In contrast, in head-final languages like Japanese, the negative polarity item precedes the negative head, and because it is dependent on the negative head for licensing, it projects its licensor (e.g., negation). This difference in the position of the head in relation to its complement in Japanese and English allows for higher projectability of the actual item in Japanese. It is important to note that while initial core arguments in English may project the syntactic category, they do not necessarily project the actual lexical item to fill that slot. As in Japanese, there is a need to investigate further the role of semantic/pragmatic projectability in English co-constructions.

Finally, Fox et al. (1996) and Hayashi (1999) claimed that Japanese coparticipants have to "wait to see." However, as the onion metaphor suggests, with co-constructions that begin with outer level components, they may also have to "wait to say," because highly projectable final elements may only come after less projectable inner level components and elements.

\section{References}

Fox, Barbara A., Makoto Hayashi, \& Robert Jasperson. 1996. Resources and repair: a cross-linguistic study of syntax and repair. In E. Ochs, E. A. Schegloff \& S. A. Thompson (eds.) Interaction and grammar, 185-137. Cambridge: Cambridge University Press.

Hata, Iku. 1991. Dai-itibu hukusiron no keehu (Chapter 1: Lineage of adverb theory). Nihongo kyooiku sidoo sankoosyo 19, 1-46. Tokyo: National Language Research Institute, Ookurasyoo. 
Hayashi, Makoto. 1999. Where grammar and interaction meet: A study of coparticipant completion in Japanese conversation. Human Studies 22:375-499.

Jones, Kimberly. 1990. Conflict in Japanese conversation. PhD dissertation, University of Michigan.

Jorden, Eleanor Harz with Mari Noda. 1987. Japanese: the spoken language. New Haven: Yale University Press.

Kuwabara, Kazuko. 1995. Teean no koozoo to sutoratezii no koosatu (Investigation of the structure of proposals and strategies). Japan Women's University, MA Thesis.

Kuwabara, Kazuko. 1996. Nihongo no "teean" no danwa no koozoo bunseki (Structural analysis of Japanese proposal discourse). Nihon Zyosi Daigaku Daigakuin Bungaku Kenkyuuka Kiyoo 2:1-12.

Lerner, Gene H. 1991. On the syntax of sentences-in-progress. Language in Society 20:441-458.

Minami, Fujio. 1964. Hukubun (Complex sentences). Kooza gendaigo 6 Koogo bunpoo no mondaiten, 71-89. Tokyo: Meezi Syoin.

Minami, Fujio. 1974. Gendai nihongo no koozoo (The structure of modern Japanese). Tokyo: Taisyuukan Syoten.

Minami, Fujio. 1993. Gendai nihongo bunpoo no rinkaku (Outline of the grammar of modern Japanese). Tokyo: Taisyuukan Syoten.

Minami, Fujio. 1997. Gendai nihongo kenkyuu (Studies on modern Japanese). Tokyo: Sanseedoo.

Mizutani, Nobuko. 1993. Kyoowa kara taiwa e (From co-constructed talk to dialogic talk). Nihongogaku 12:4:4-10.

Nagano, Masaru. 1952. "Kara" to "no de" to wa doo tigau ka (How do kara 'because' and no de 'because' differ?). Kokugo to Kokugogaku 334.

Ono, Tsuyoshi \& Eri Yoshida. 1996. A study of co-construction in Japanese: We don't "finish each other's sentences." In N. Akatsuka, S. Iwasaki \& S. Strauss (eds.) Japanese/Korean linguistics 5, 115-130. Stanford: CSLI.

Sacks, Harvey, Emanuel Schegloff, \& Gail Jefferson. 1974. A simplest systematics for the organization of turn-taking in conversation. Language 50:4:696-735.

Sakuma, Mayumi, Seiju Sugito, \& Kanichi Hanzawa. 1997. Nihongo no bunsyoo/danwa (Japanese discourse/conversation). Tokyo: Oohuu.

Szatrowski, Polly. 1993. Nihongo no danwa no koozoo bunseki- kanyuu no sutoratezii no koosatu- (Structure of Japanese conversation- invitation strategies). Tokyo: Kurosio.

Szatrowski, Polly. 2000. Kyoodoo hatuwa ni okeru sankasya no tatiba to gengo/higengo koodoo no kanren ni tuite (Relation between participant status and verbal/nonverbal behavior in co-construction). Nihongo Kagaku (Japanese Linguistics) 7:4:44-69.

Szatrowski, Polly. (to appear) When do Japanese speakers co-construct utterances? In M. Noda \& P. Wetzel (eds.) Language in culture. Columbus, $\mathrm{OH}$ : Ohio State University Press. 


\section{University of Minnesota- ILES}

215 Nolte Center

Minneapolis, MN 55455

szatr001@tc.umn.edu 


\section{Syntactic Projectability in Japanese Conversation}

Table 1: Components and Elements of Subordinate Clauses (Minami 1993:96-97, Minami 1964:85; bold lines and roman numerals on top added by Szatrowski) ${ }^{4}$

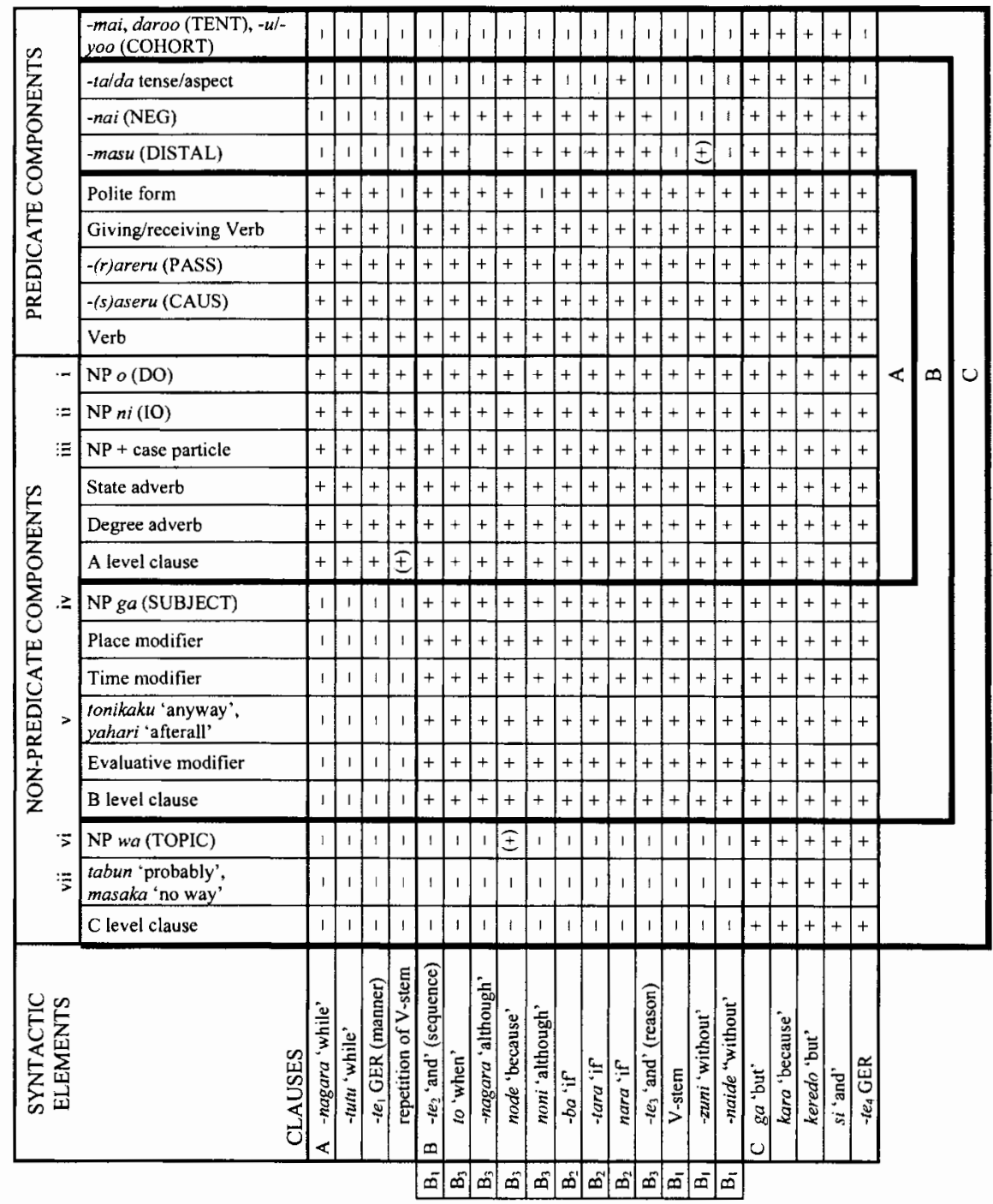

\footnotetext{
${ }^{4}$ I have indicated the 3 levels A, B, and C with bold lines in this table. Minami divides sentences into the non-predicate components and predicate elements given across the top of the table. $\mathrm{He}$ determined the level for each of the different components and elements based on their possible occurrence in the clauses given on the left. A '+' sign indicates that a component/ element can occur, and a '-' sign that it cannot.
} 